\title{
Application of Adaptived Fuzzy PID Control in New Heating System
}

\author{
Honghui $\mathrm{Mu}$ \\ (ChangChun University of Science And Technology, Chang chun, Jil in \\ 130600,China) \\ 270331219@qq.com
}

\begin{abstract}
In household heat metering, the user can according to need, through the electromagnetic valve opening and closing frequency to achieve temperature regulation. The heating system is a nonlinear, slow time-varying, lag deposit and other characteristics, usually by fuzzy PID control system. This paper adopts the improved adaptive fuzzy PID control system, through simulation, this scheme improves the robustness of new heating system.
\end{abstract}

Keywords: fuzzy control; adaptive; Heating household metering

\section{Introduction}

In the heating period, the heating energy consumption of urban residents in north China accounts $40 \%$ of the whole country. Due to the heating is still charged from the residential area, it is seriously wasting the resource. Foreign experience shows that installing heat meter flow meter, a household metering heating, with "multi-purpose hot, more pay" principle, energy saving $20 \% \sim 30 \%$. The user can according to requirement to adjust the indoor temperature. The benefit is not only saving the cost of living, but also reducing the pollution to the environment. The basic structure of the new system is shown in Figure 1.

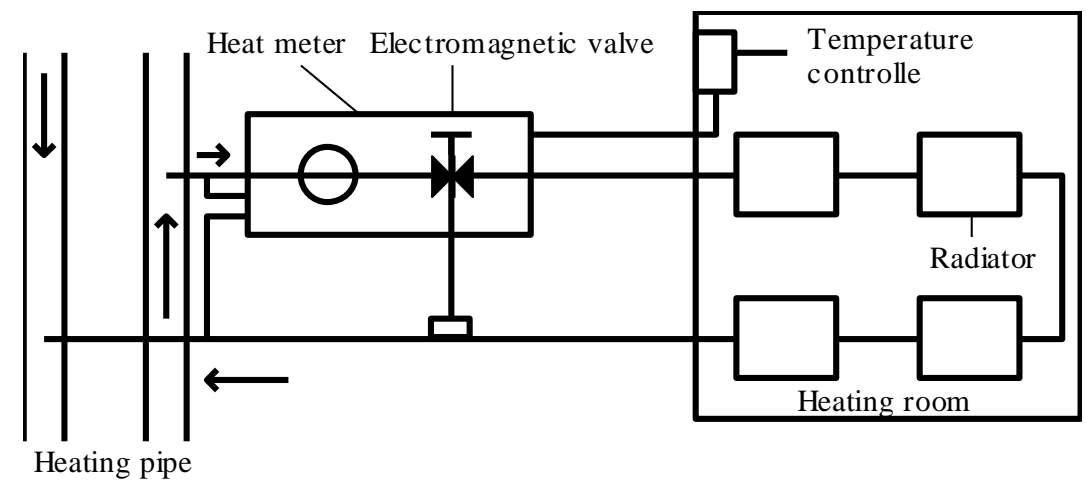

Figure 1.The New Type of Heating Metering System Structure Diagram

As shown in Figure 1, based on this double pipe heating system, the user is mainly through the electromagnetic valve opening and closing frequency variable flow control, different implementation heating pipe to change the total pressure difference system, to adjust the room temperature. Because the user's heat load along with the change of external temperature and weather changes, has the characteristics of nonlinear, timevarying, pure lag, difficult to establish accurate mathematical model .Additionally, regulate the temperature of the water supply, quick adjustment will lead to temperature overshoot, range [2]. And if the adjustment too slow, will lead to the response time is too 
long, at the same time it can't meet the system requirements. The conventional PID controller has its own drawback due to if its parameter is fixed then unable to adaptive changing the temperature of the heating system in real time. Fuzzy PID control can effectively solve the household heating metering system many problems, such as big inertia, pure time-delay and time-varying difficult to control. This paper adopts the fuzzy control method, and carries on the improvement.

\section{A Fuzzy PID Controller}

Fuzzy PID controller is combined with the traditional PID controller and fuzzy controller. With fuzzy rules and using the ideas of fuzzy theory, according to the different deviation E, deviation change rate EC for PID parameter , $K_{I}$ and $K_{D}$ for on-line selftuning. A fuzzy PID controller structure diagram ${ }^{p}$ as shown in Figure 2.

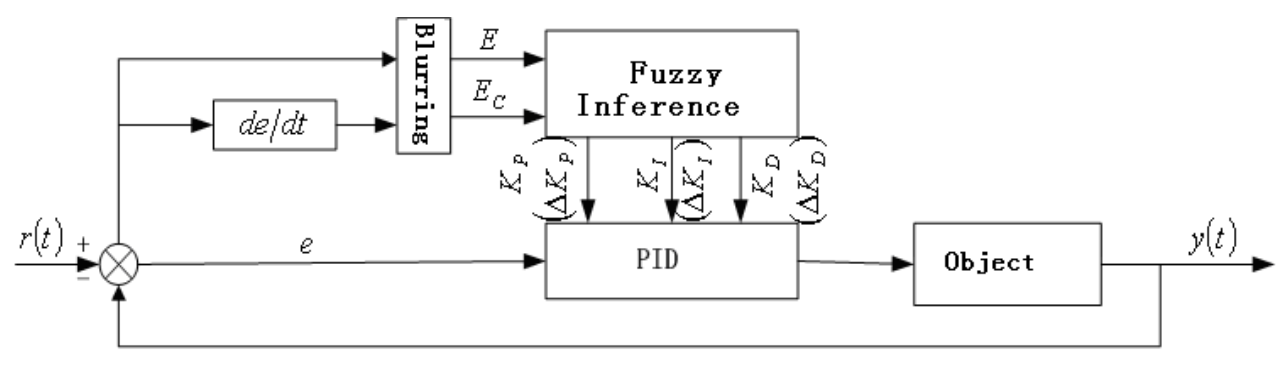

Figure 2. Basic Structure of Fuzzy Controller

The heating system normally uses fuzzy control algorithm (Figure 3), and the system first uses the PD controller to control system. And then increase the integral link, solve the problem of fuzzy PD controller can't eliminate the steady-state error, and said for fuzzy PD + linear I. This kind of Fuzzy - PID control has a faster dynamic response than the PID control, a smaller overshoot, and it has a higher steady-state accuracy than the Fuzzy control.

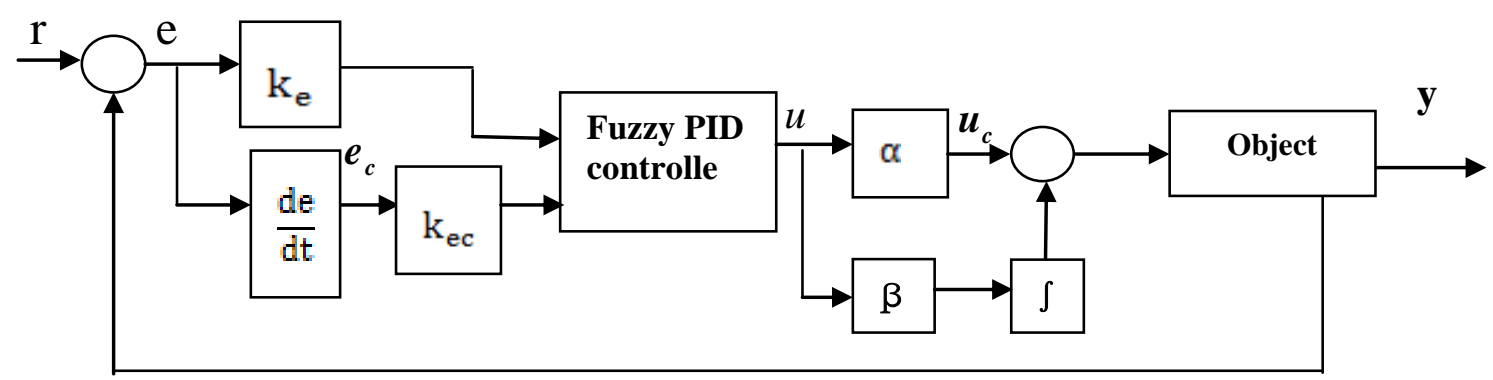

Figure 3. Fuzzy PID Control System

The relationship between input and output shows as follow: the A is the fuzzy subset of the deviation e, $\mathrm{B}$ is the fuzzy subset of the deviation change rate ec.

$$
\mathrm{u}_{\mathrm{c}}=\alpha \mathrm{A}+\beta \mathrm{At}+\left(\alpha \mathrm{k}_{\mathrm{e}} \mathrm{P}+\beta \mathrm{k}_{\mathrm{ec}} \mathrm{D}\right) \mathrm{e}+\beta \mathrm{k}_{\mathrm{e}} \mathrm{p} \int \mathrm{edt}+\alpha \mathrm{k}_{\mathrm{ec}} \mathrm{De}
$$

Proportional coefficient: $\alpha \mathrm{k}_{e} \mathrm{P}+\beta \mathrm{k}_{\mathrm{ec}} \mathrm{D}$, integral coefficient: $\beta \mathrm{k}_{\mathrm{e}} \mathrm{p}$, differential coefficient: $\alpha \mathrm{k}_{\mathrm{ec}} \mathrm{D}$, among them, parameters $\mathrm{k}_{\mathrm{ec}}$ affect the proportional and differential coefficient of controller, $\beta$ affect the proportional and integral coefficients, so through the regulation of the two coefficients can realize a controller proportional integral differential coefficient of adjusting ${ }^{[1]}$. 


\section{The Adaptive Fuzzy PID Controller}

In order to improve the fuzzy PID controller, changing the polarity of the e ahead of time and adding some damping can prevent the output due to the rate of change is too big deviation from a given again. This is more advantageous to reduce the adjustment time and recovery time.

The adaptive fuzzy PID referred to as the FAPID controller, the system structure is shown in Figure 4. The dotted line part of the fuzzy adaptive controller, $G_{P}(s)$ for the transfer function of controlled object.

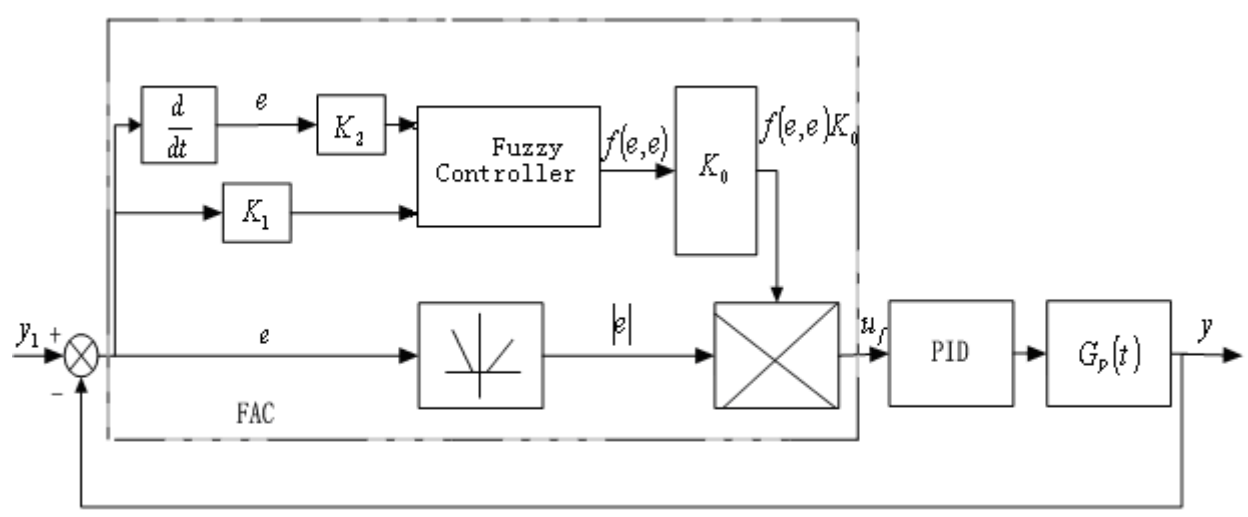

Figure 4. FAPID Control System Structure Diagram

When the controlled system breaks, the structure interference or the state interference appears. The transient response according to the size of the E and EC transient value, there are nine possible situations. When the system sampling to response value, will be response value with the given value and the next trend, according to the existing system control knowledge, by use of the fuzzy control method, intensify or reduce efforts to control, appropriate to stem a response to a change in the direction of the deviation from the given, make the output tends to be given as soon as possible.

Set $\mathrm{E}$ means language variable deviation, EC said deviation change rate, the universe $X_{e}=\left\{\begin{array}{llllll}-6,-5,-4,-3,-2,-1, & -4,+1,+2,+3,+4,+5,+6\end{array}\right\}$

$E$ and $E C$ have seven linguistic variables in their universe: PB 、PM、PS、Z、NS、 NM、NB.Using T-S fuzzy model, fuzzy control table can be derived (Table 1). $g_{1}(\mathrm{e})$ 、 $g_{2}(\mathrm{e}) 、 g_{3}(\mathrm{e})$ are selected for $K_{0}|e| 、 0.6 \mathrm{~K}_{0}|e|$ and $0.3 \mathrm{~K}_{0}|e|$. 
Table 1. Fuzzy Control Query Table (The value of $u_{f}$ )

\begin{tabular}{|c|c|c|c|c|c|c|c|}
\hline $\begin{array}{c}\mathrm{E} \\
\mathrm{EC}\end{array}$ & $\mathrm{PB}$ & $\mathrm{PM}$ & $\mathrm{PS}$ & $\mathrm{Z}$ & $\mathrm{NS}$ & $\mathrm{NM}$ & $\mathrm{NB}$ \\
\hline $\mathrm{PB}$ & $g_{1}(e)$ & $g_{1}(e)$ & $g_{2}(e)$ & $g_{3}(e)$ & 0 & 0 & 0 \\
\hline $\mathrm{PM}$ & $g_{1}(e)$ & $g_{1}(e)$ & $g_{2}(e)$ & 0 & 0 & 0 & $-g_{3}(e)$ \\
\hline $\mathrm{PS}$ & $g_{1}(e)$ & $g_{2}(e)$ & $g_{3}(e)$ & 0 & 0 & $-g_{3}(e)$ & $-g_{2}(e)$ \\
\hline $\mathrm{Z}$ & $g_{1}(e)$ & $g_{3}(e)$ & 0 & 0 & 0 & $-g_{3}(e)$ & $-g_{1}(e)$ \\
\hline $\mathrm{NS}$ & $g_{2}(e)$ & $g_{3}(e)$ & 0 & 0 & $-g_{3}(e)$ & $-g_{2}(e)$ & $-g_{1}(e)$ \\
\hline $\mathrm{NM}$ & $g_{3}(e)$ & 0 & 0 & 0 & $-g_{2}(e)$ & $-g_{1}(e)$ & $-g_{1}(e)$ \\
\hline $\mathrm{NB}$ & 0 & 0 & 0 & $-g_{3}(e)$ & $-g_{2}(e)$ & $-g_{1}(e)$ & $-g_{1}(e)$ \\
\hline
\end{tabular}

The membership function of fuzzy subsets are piecewise linear function. According to the literature [3] given fuzzy reasoning algorithm, then can get fuzzy control query table which shows in Table 2.

The output of the fuzzy adaptive controller $u_{f}=f(e, e) K_{0}|e|=K|e|$

$K=f(e, e) K_{0}, f$ is a non-linear function relation which is fixed by fuzzy control query table. The PID output as follows:

$$
u=K_{p}\left(u_{f}+\frac{1}{T_{i}} \int u_{f} d t+T_{d} \frac{d u_{f}}{d t}\right)
$$

The Table 2 shows that except $e \cdot e c<0$ and $\left|x_{e}\right| \leq 1$, then $K|e| \neq|K|$ e , the rest of the case is : $\mathrm{K}|e|=|K| \mathrm{e}$, then

$$
u=K_{c}\left(e+\frac{1}{T_{i}} \int e d t+T_{d} \frac{d e}{d t}\right)
$$

In Type, $K_{c}=K_{p} \cdot|K|=|f(e, e)|=K_{o} K_{p}$. Accordingly, the FAPID controller gain is the nonlinear function of the system state. The fuzzy adaptive controller plays a role in adjusting the proportion coefficient of PID controller dynamically.

when $e \cdot e c<0$ and $\left|x_{e}\right| \leq 1$, the system output tends to a given result.

Table 2. Fuzzy Control Query Table(The value of $\mathrm{f}$ )

\begin{tabular}{|c|c|c|c|c|c|c|c|c|c|c|c|c|c|}
\hline \multirow{2}{*}{$x_{e}$} & \multicolumn{10}{|c|}{$x_{e c}$} \\
\cline { 2 - 13 } & -6 & -5 & -4 & -3 & -2 & -1 & 0 & +1 & +2 & +3 & +4 & +5 & +6 \\
\hline-6 & -1 & -1 & -0.93 & -0.82 & -0.66 & -0.46 & -0.35 & -0.3 & -0.3 & 0.3 & 0.3 & 0.3 & 0.3 \\
\hline-5 & -1 & -1 & -0.9 & -0.81 & -0.65 & -0.45 & -0.34 & -0.3 & -0.3 & 0.3 & 0.3 & 0.3 & 0.3 \\
\hline-4 & -0.97 & -0.95 & -0.87 & -0.77 & -0.62 & -0.44 & -0.33 & -0.3 & 0.1 & 0.32 & 0.35 & 0.38 & 0.4 \\
\hline-3 & -0.96 & -0.91 & -0.85 & -0.67 & -0.53 & -0.41 & -0.32 & -0.3 & 0.1 & 0.34 & 0.38 & 0.4 & 0.43 \\
\hline-2 & -0.92 & -0.83 & -0.71 & -0.58 & -0.5 & -0.36 & -0.31 & 0 & 0.3 & 0.36 & 0.41 & 0.46 & 0.53 \\
\hline
\end{tabular}




\begin{tabular}{|c|c|c|c|c|c|c|c|c|c|c|c|c|c|}
\hline-1 & -0.86 & -0.77 & -0.66 & -0.48 & -0.35 & -0.3 & -0.3 & 0 & 0.3 & 0.38 & 0.47 & 0.51 & 0.6 \\
\hline 0 & -0.8 & -0.67 & -0.5 & -0.4 & -0.3 & 0 & 0 & 0 & 0.3 & 0.4 & 0.5 & 0.67 & 0.8 \\
\hline+1 & -0.6 & -0.51 & -0.47 & -0.38 & -0.3 & 0 & 0 & 0.3 & 0.35 & 0.48 & 0.66 & 0.77 & 0.86 \\
\hline+2 & -0.53 & -0.46 & -0.41 & -0.36 & -0.3 & 0 & 0.3 & 0.36 & 0.5 & 0.58 & 0.71 & 0.83 & 0.92 \\
\hline+3 & -0.43 & -0.4 & -0.38 & -0.34 & -0.1 & 0.3 & 0.3 & 0.41 & 0.53 & 0.67 & 0.85 & 0.91 & 0.96 \\
\hline+4 & -0.4 & -0.38 & -0.35 & -0.32 & -0.1 & 0.3 & 0.3 & 0.44 & 0.62 & 0.77 & 0.87 & 0.95 & 0.97 \\
\hline+5 & -0.3 & -0.3 & -0.3 & -0.3 & 0.3 & 0.3 & 0.3 & 0.45 & 0.65 & 0.81 & 0.9 & 1 & 1 \\
\hline+6 & -0.3 & -0.3 & -0.3 & -0.3 & 0.3 & 0.3 & 0.3 & 0.46 & 0.66 & 0.82 & 0.93 & 1 & 1 \\
\hline
\end{tabular}

The stability of the system is discussed as below:

Theorem1:for linear time-invariant SISO minimum phase systems, the sufficient and necessary conditions for the FAPID closed-loop control system stability is:

$$
K_{0} \leq k_{c} \prod_{j=1}^{m}\left(-z_{j}\right) / K_{k} \prod_{i=1}^{n_{1}}\left(-p_{i}\right)
$$

In the formula, $k_{c}$ is the $\mathrm{k}$ value which corresponds the root locus for the closed-loop system with a virtual axis intersection point. That is, the critical stability of the system root locus parameter $\mathrm{k}$ values. $K_{k}$ is an open-loop amplification factor when the fuzzy adaptive controller is not included, $z_{j}(j=1,2, \ldots, m), p_{i}\left(i=1,2, \ldots, n_{1}\right)$ for open loop of nonzero and pole.

Theorem 2:for linear time-invariant SISO minimum phase systems, the sufficient and necessary conditions for the FAPID closed-loop control system stability is:

$$
\frac{k_{c 1}}{\min \left(|f(e, e)| 2 K_{k}\right)}\left|{ }_{j=1}^{m}\left(-z_{j}\right) / \prod_{i=1}^{n_{1}}\left(-p_{i}\right)\right| \leq K_{0} \leq \frac{k_{c 2}}{K_{k}}\left|\prod_{j=1}^{m}\left(-z_{j}\right) / \coprod_{i=1}^{n_{1}} \mathbf{I}\left(-p_{i}\right)\right|
$$

In the formula, $k_{c_{1}}$ and $k_{c_{2}}$ as the critical stability of the system root locus parameter $\mathrm{k}$ value. $\min (\cdot)$ takes the minimum non-zero value (.).

From the above theorem, the appropriate $k_{0}$ can guarantee the system stability. When object is non-minimum phase system, the absolute value of the minimum non-zero elements in fuzzy control is query table not too small, otherwise, the value of $\mathrm{K}$ that meet the FAPID closed-loop control necessary and sufficient conditions for the robust stability of the system would not exist. This requirement is sometimes conflict with the results of fuzzy reasoning. But this kind of situation usually occurs when the absolute value of the error is smaller, through logical switch at this time, the system switches to control by PID regulator alone, can solve the stability problem well.

\section{Fuzzy PID and Conventional PID Simulation Comparison}

In modern industrial production process, many industrial process object properties can be used second order inertial link with pure delay link. A new type of heating system control structure as shown in Figure 5, according to its working characteristics, frequency converter and circulating pump are approximate equivalent to first-order inertia link. Therefore, the mathematical model of the heating system can be equivalent to two inertial link with pure hysteresis in series, the approximate model selection for: 


$$
G(s)=\frac{10 e^{-40 \tau}}{(50 s+1)(s+1)}
$$
Set the return wate
temperature

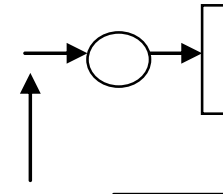

Fuzzy PID controller

\section{Inverter}

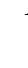

\section{Tempe}

The return water temperature

\section{Figure 5. Structure of a New Heating System}

In heating system, the return water temperature is controlled by temperature sensor which returns to the set end. Its value can reflect the system's demand in the heat. According to the change of outdoor temperature at any time to change the return water temperature setting value, for example, when the temperature outside is a $\mathbf{- 2 4} \mathbf{C}^{\circ}$, the return water temperature can be set at $\mathbf{6 0}^{\circ} \boldsymbol{C}$. Traditional PID Simulink model is as follows:

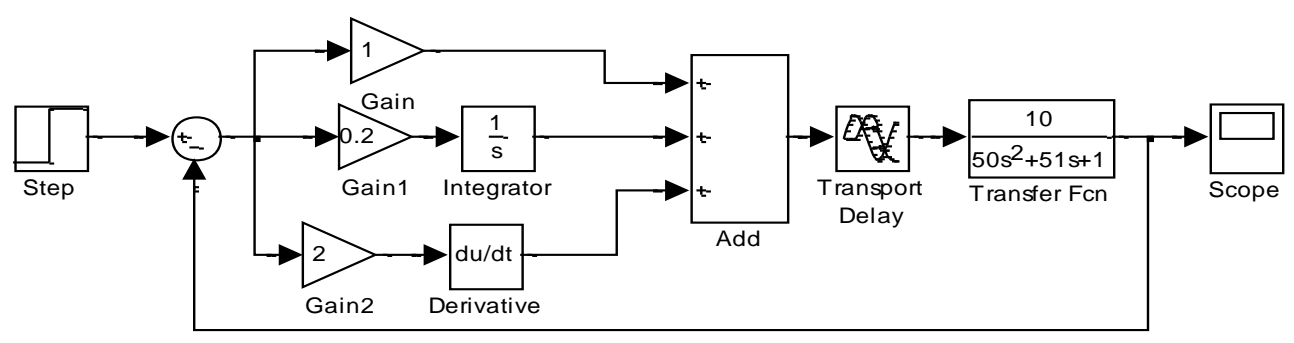

Figure 6. The Traditional PID Model Diagram

In fuzzy control, the actual water temperature and set temperature is difference value. And the temperature change rate of ec, both as input, with the change of the frequency converter input voltage value as the output $\mathrm{u}$, set $\mathrm{E}, \mathrm{EC}, \mathrm{U}$ of the value of language variables respectively, the universe is $(-6,-5,-4,-3,-2,-1,0,+1,+2,+3,+4,+5,+6)$, The experiment measured the deviation of the return water temperature for $\left[-6^{\circ} \boldsymbol{C ,}, \mathbf{6}^{\circ} \mathbf{C}\right]$, the rate of change of deviation for $\left[-3^{\circ} \mathbf{C} / s, 3^{\circ} \mathbf{C} / s\right]$, the output of the controller for $[-30 \mathrm{~V}, 30$ V]. Three quantities corresponding to the fuzzy subsets are as follows :[NB, NM, NS, ZO, PS, PM, PB], membership function to choose triangle, the rule table is as follows:

Table 3. Fuzzy Controller Control Rules Table

\begin{tabular}{|c|c|c|c|c|c|c|c|}
\hline EC & NB & NM & NS & ZO & PS & PM & PB \\
\hline NB & PB & PB & PM & PM & PS & ZO & ZO \\
\hline NM & PB & PB & PM & PS & PS & ZO & NS \\
\hline NS & PM & PM & PM & PS & ZO & NS & NM \\
\hline ZO & PM & PM & PS & ZO & NS & NM & NM \\
\hline PS & PS & PS & ZO & NS & NS & NM & NM \\
\hline PM & PS & ZO & NS & NM & NM & NB & NB \\
\hline PB & ZO & ZO & NM & NM & NM & NB & NB \\
\hline
\end{tabular}


The Simulink model of the fuzzy PID is as following, including alpha $=0.2$, beta $=$ 0.01, Fuzzy_PID is the subsystem for fuzzy PID controller.

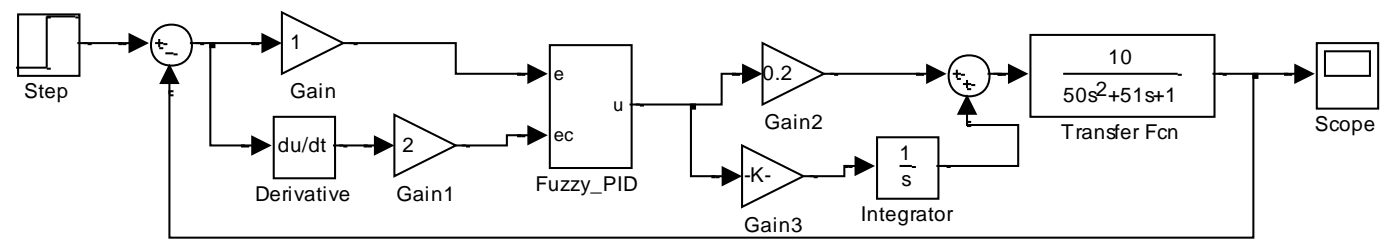

Figure 7. Fuzzy PID Model Diagram

By using Simulink simulation, the simulation results of the traditional PID control and fuzzy PID control is shown in Figure 8:

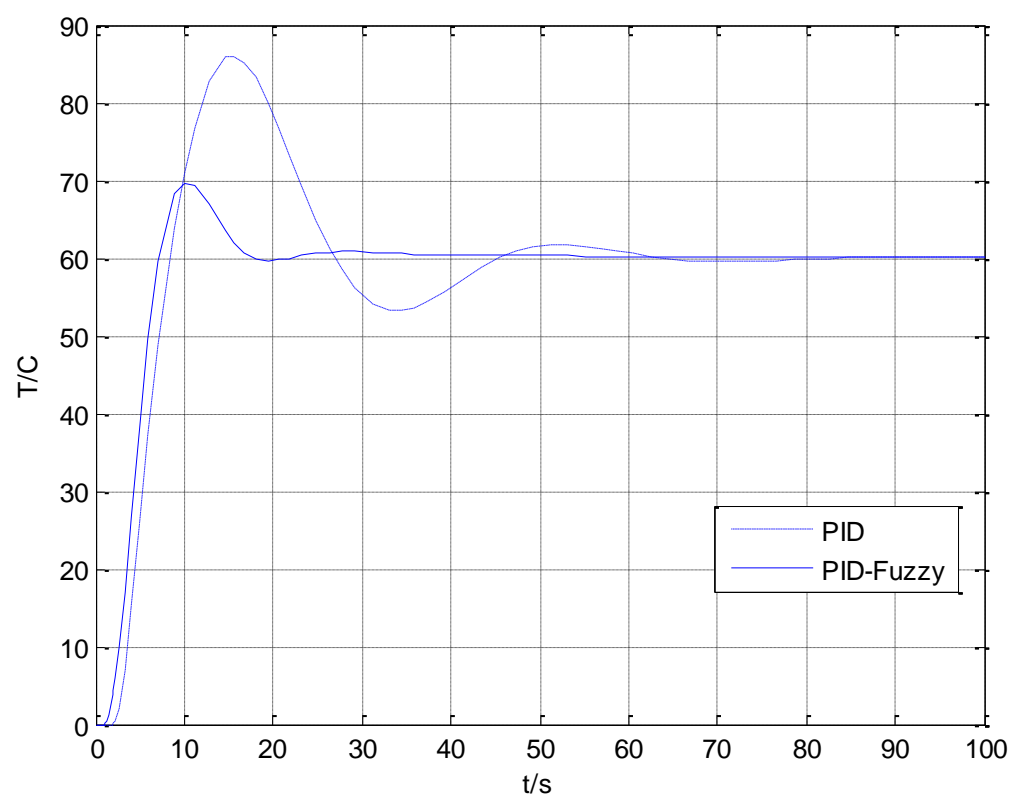

Figure 8. Comparison of Traditional PID Control and Fuzzy PID Control

Through the simulation experiment we can see that in the same condition the traditional PID control overshoot is larger, and when the 80s system still has a large steady-state error. Using fuzzy control, when the return water temperature is $60^{\circ} \mathrm{C}$, the system after 58s can achieve stability, and smaller overshoot than traditional PID control. Thus, fuzzy PID control has better control quality.

\section{The Adaptive Fuzzy PID Controller and Fuzzy PID Controller Simulation Comparison}

The model diagram of the adaptive fuzzy PID controller is as follows, where PID is a conventional PID controller, $\quad k_{1}=0.5, k_{2}=0.1, k_{p}=0.15, k_{i}=0.0015, k_{d}=2$ 


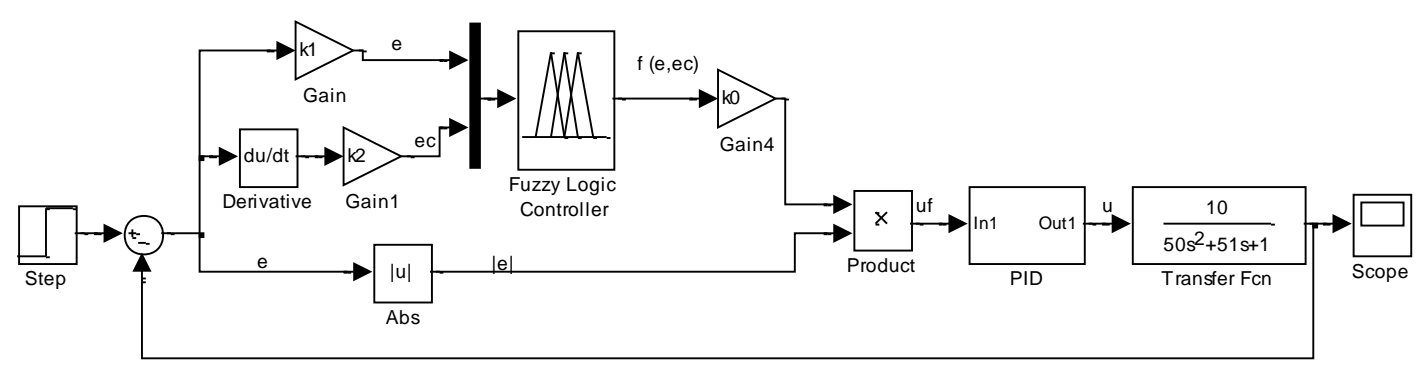

Figure 9. The Adaptive Fuzzy PID Model Diagram

According to the heating characteristics of new heating system, Through calculating the error e and error rate ec, Using fuzzy rules of fuzzy inference, $k_{p}, k_{i}, k_{d}$ of the fuzzy control table is as follows:

Table 4. Fuzzy Controller Control Rules Table of $k_{p}$

\begin{tabular}{|c|c|c|c|c|c|c|c|}
\hline EC & NB & NM & NS & $Z$ & PS & PM & PB \\
\hline NB & PB & PB & PM & PM & PS & $Z$ & $Z$ \\
\hline NM & PB & PB & PM & PS & PS & Z & NS \\
\hline NS & PM & PM & PM & PS & Z & NS & NS \\
\hline Z & PM & PM & PS & Z & NS & NM & NM \\
\hline PS & PS & PS & Z & NS & NS & NM & NM \\
\hline PM & PS & Z & NS & NM & NM & NM & NB \\
\hline PB & Z & $Z$ & NM & NM & NM & NB & NB \\
\hline
\end{tabular}

Table 5. Fuzzy Controller Control Rules Table of $k_{i}$

\begin{tabular}{|l|l|l|l|l|l|l|l|}
\hline $\begin{array}{c}\text { EG } \\
\text { E }\end{array}$ & NB & NM & NS & Z & PS & PM & PB \\
\hline NB & NB & NB & NM & NM & NS & Z & Z \\
\hline NM & NB & NB & NM & NS & NS & Z & Z \\
\hline NS & NM & NM & NS & NS & Z & PS & PS \\
\hline Z & NM & NM & NM & Z & PS & PM & PM \\
\hline PS & NM & NS & Z & PS & PS & PM & PB \\
\hline PM & Z & Z & PS & PS & PM & PB & PB \\
\hline PB & Z & Z & PS & PM & PM & PB & PB \\
\hline
\end{tabular}


Table 6. Fuzzy Controller Control Rules Table of $k_{d}$

\begin{tabular}{|l|l|l|l|l|l|l|l|}
\hline $\begin{array}{l}\text { EG } \\
\text { E }\end{array}$ & NB & NM & NS & Z & PS & PM & PB \\
\hline NB & PS & NS & NB & NB & NB & NM & PS \\
\hline NM & PS & NS & NB & NM & NM & NS & Z \\
\hline NS & Z & NS & NM & NM & NS & NS & Z \\
\hline Z & Z & NS & NS & NS & NS & NS & Z \\
\hline PS & Z & Z & Z & Z & Z & Z & Z \\
\hline PM & PB & NS & PS & PS & PS & PS & PB \\
\hline PB & PB & PM & PM & PM & PS & PS & PB \\
\hline
\end{tabular}

The Adaptive fuzzy PID control and fuzzy PID control simulation are shown in the following figure. The improved controller only need 30s can achieve stability and is no overshoot, thus, the improved system has better control characteristics.

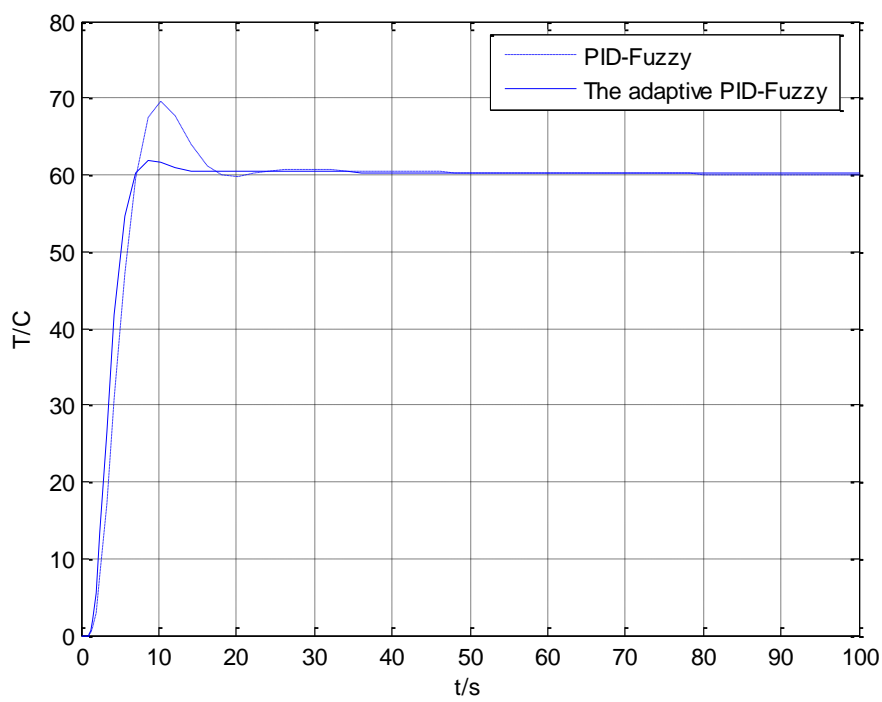

Figure 10. Comparison of Adaptive Fuzzy PID Control and Fuzzy PID Control

\section{Conclusion}

New type of heating system is a nonlinear, big lag system. In this paper, we based on fuzzy control, and put forward the adaptive fuzzy controller, to improve the control quality of control system. Adaptive fuzzy PID control system greatly improve the robustness of the system, greatly reduce the amount of overshoot and improve the ability of anti-jamming, shortened the time adjustment.

\section{References}

[1] H. Wei, Z. Ying and Y.-X. Ling, "Research of a Self-organizing Fuzzy PID Controller in LED die Source-measure System", 8th World Congress on In-telligent Control and Automation, Jinan, (2010), pp. 2542-2547.

[2] Y. Yu and Y. Liu, "Application of improved PID fuzzy control in new heating system", Industrial instrumentation and automation device, vol. 6, (2012), pp. 40-45.

[3] W.-H. Huang, "Fuzzy Control System and Its Application, Publishing House of Electronics Industry", (2012), pp. 77-123. 
[4] S. E. Mansour, G. C. Kember and R. Dubay, "Online optimization of fuzzy-PID control of a thermal process", ISA Transactions, vo. 44, no. 2, (2005), pp. 305-314.

[5] Q. Du, W.-D. Zou and A. Lou, "Fuzzy-PID for semiconductor laser temperature control system", Journal of Nanchang Hang-kong University(Natural Science), vol. 20, no. 1, (2006), pp. 4-7.

[6] X.-H. Jing and L.-P. Song, "Variable Fertilization Syste m for Adaptive Fuzzy PID and PI Control", Journal of Agricultural Mechanization Research, vol. 10, (2015), pp. 29-33.

[7] W.-X. Xiao, J.-G. Wang and X.-Q. Ma, "Self-adaptive Differential Evolution Algorithm and Its Application to Complex Optimization Problems", Journal of Harbin University of Science and Technology, vol. 01, (2015).

[8] P.-X. Rong, W.-B. Dong, L. Yu and C.-W. Yang, "Research and Application of Self Tuning Fuzzy PID Controller Based on Chaos Theory", Journal of Harbin University of Science and Technology, vol. 02, (2014). 